\title{
In vitro and computational analysis of the putative furin cleavage site (RRARS) in the divergent spike protein of the rodent coronavirus AcCoV-JC34 (sub-genus luchacovirus)
}

\author{
Annette Choi ${ }^{1 *}$, Deanndria T. Singleton ${ }^{1 *}$, Alison E. Stout ${ }^{1}$, Jean K. Millet ${ }^{2}$ \\ and Gary R. Whittaker ${ }^{1,3 \#}$
}

Departments of Microbiology \& Immunology ${ }^{1}$ and Public \& Ecosystem Health ${ }^{3}$, College of Veterinary Medicine, Cornell University, Ithaca, NY, 14853, USA.

Université Paris-Saclay, INRAE, UVSQ, Virologie et Immunologie Moléculaires, Jouyen-Josas, France ${ }^{2}$

\# - corresponding author grw7@cornell.edu 


\section{Abstract}

The Coronaviridae is a highly diverse virus family, with reservoir hosts in a variety of wildlife species that encompass bats, birds and small mammals, including rodents. Within the taxonomic group alphacoronavirus, certain sub-genera (including the luchacoviruses) have phylogenetically distinct spike proteins, which remain essentially uncharacterized. Using in vitro and computational techniques, we analyzed the spike protein of the rodent coronavirus AcCoV-JC34 from the sub-genus luchacovirus, previously identified in Apodemus chevrieri (Chevrier's field mouse). We show that AcCoV-JC34 — unlike the other luchacoviruses—has a putative furin cleavage site (FCS) within its spike S1 domain, close to the S1/S2 interface. The pattern of basic amino acids within the AcCoV-JC34 FCS (-RR-R-) is identical to that found in "pre-variant" SARS-CoV-2 - which is in itself atypical for an FCS, and suboptimal for furin cleavage. Our analysis shows that, while containing an -RR-R-motif, the AcCoVJC34 spike "FCS" is not cleaved by furin (unlike for SARS-CoV-2), suggesting the possible presence of a progenitor sequence for viral emergence from a distinct wildlife host. 


\section{Introduction}

The animal reservoirs for pandemic potential viruses (including coronaviruses) are focused on the breadth of bat species (order Chiroptera) that exist around the world [1-3]. However certain coronaviruses, notably the sub-genus embecovirus (genus betacoronavirus) currently have no bat-origin examples and have a putative reservoir in animal species within the order Rodentia, which is the most diverse mammalian order on the planet and is well-documented as an important reservoir host for human diseases $[4,5]$.

While rodents are generally appreciated as an important reservoir for RNA viruses, surveillance and detection of coronaviruses is currently relatively limited. Following the initial discovery of what is now the prototype luchacovirus (Lucheng Rn rat coronavirus, or LRNV), along with two Betacoronavirus species [6], a study from Ge et al. examined 177 intestinal samples from three species of rodents in Yunnan Province, China and detected both alphacoronaviruses and betacoronviruses in three animal species (Apodemus chevrieri, Eothenomys fidelis and Apodemis ilex) [7]. Their study reported the full-length genome of a coronavirus (AcCoV-JC34) from A. chevrieri (Chevrier's field mouse) that was designated an alphacoronavirus (sub-genus luchacovirus) based on its genome structure and multiple sequence alignments, which included analysis of the whole genome and the ORF1a/b genes. However, Ge et al. noted that both AcCoV-JC34 and LRNV may represent a novel alphacoronavirus species. In particular, they noted that the luchacovirus $\mathrm{S}$ gene formed a distinct genetic lineage with low sequence identity $(<25 \%)$ compared to other well characterized coronaviruses. Ge at al. also noted that AcCoV-JC34 S contained two predicted 
proteolytic cleavage sites, one at residue 508 at the S1/S2 interface, and the other at residue 674 (the fusion peptide-proximal S2' position).

More recently, a more comprehensive sampling of rodents and other small mammals has identified a diverse range of coronaviruses in such animal reservoirs [8]. To determine the evolutionary history of rodent alphacoronaviruses in more detail, Tsoleridis $e t$ al. also reported sequence data from viruses sampled from European rodents, to define a single common ancestor for all rodent alphacoronaviruses with a shared recombinant betacoronavirus spike gene_-also shared with batCoV HKU2, swine acute diarrhea syndrome (SADS) coronavirus and two shrew coronaviruses [9]. According to Tsoleridis et al., the luchacoviruses (including AcCoV-JC34) comprised a distinct lineage within the "recombinant" viruses. In summary, it can be argued that coronaviruses of small mammals, including rodents, are still poorly understood.

We have previously reported that rodent coronavirus AcCoV-JC34 has a weakly predicted furin cleavage site (FCS) is its spike protein [10]. Here, we further analyze the AcCoV-JC34 spike and its "FCS" along with the other luchacoviruses, taking an in vitro and computational perspective.

\section{Results}

\section{Phylogenetic analysis of luchacoviruses}

To understand the relationship of $\mathrm{ACoV}-\mathrm{JC} 34$ and the other known luchacoviruses, we first constructed a phylogenetic tree of these viruses in comparison to representatives of the diverse coronavirus family, based on spike protein sequences (Figure 1). In agreement with Ge at al., 
luchacoviruses formed a monophyletic group with 100\% bootstrap support, indicating a common ancestor origin outside of the established alphacoronavirus branch. Luchacoviruses clustered with rhinacoviruses, which include swine acute diarrhea syndrome coronavirus, Rhinolophus bat coronavirus HKU2, and porcine enteric alpha coronavirus (Figure 1).

\section{Geographical distribution of sampled luchacoviruses}

The geographical location, dates and rodent species sampled for the currently identified luchacoviruses are summarized in Figure 2 and Table 1. The luchacoviruses sampled to date are from a range of rodent hosts and are from the United Kingdom and several provinces in China (Figure 2), indicating a widespread distribution. Despite being sampled in these distinct locations, as mentioned above, luchacoviruses form a monophyletic group suggesting they have been associated with rodents for an extended period of time.

\section{Multiple sequence alignment and structural analysis of AcCoV-JC34 spike}

A multiple sequence alignment of spike proteins was performed on AcCoV-JC34 spike in comparison to the prototype luchacovirus Lucheng Rn rat CoV (LRNV), as well as SARSCoV-2, SARS-CoV, HCoV-HKU1, HCoV-OC43 and MERS-CoV. This alignment revealed that the -RR-R- motif present in AcCoV-JC34 does not align precisely with the S1/S2 motif of most coronavirus spikes (Figure 3). However, it aligned with a potential secondary MERSCoV furin cleavage site (RSTRS).

To investigate the structural location of AcCoV-JC34 furin cleavage site, the AcCoV-JC34 spike protein structure was structurally modeled (Figure 4). We used SADS-CoV spike for our modeling due to its available structure in the RCSB protein data bank and relatively high 
identity with JC34 (41.5\%). In our JC34 model, the potential furin cleavage site (-RR-R-) is located in an exposed loop of the protein which is predicted to increases its accessibility to proteases. However, the potential AcCoV-JC34 furin cleavage site was within a loop upstream of the typical S1/S2 furin cleavage site found in other CoVs (see Figure 3). In SARS-CoV-2, this upstream region aligned with a DQLTP sequence upstream of the expected S1/S2 cleavage site.

\section{Bioinformatic and biochemical analysis of potential AcCoV-JC34 spike cleavage site}

To determine whether furin processes the -RR-R- motif in AcCoV-JC34, we first utilized the PiTou and ProP furin cleavage prediction tools (Figure 5). A positive score for Pitou or a score above 0.5 for ProP indicates the likelihood of furin cleavage. AcCoV-JC34 has a weakly predicted furin cleavage site based on the PiTou score (see also [10]). Although bioinformatic tools are useful for prediction, these may not represent biologically relevant cleavage events, which need to be addressed experimentally.

To directly test whether furin cleaves this site in vitro, we performed peptide cleavage assays using furin, along with trypsin as a control. The peptide sequences used were TFMTKARART'TF (Lucheng Rn rat CoV, LRNV), TFSRRARARTL (AcCoV-JC34), and TNSPRRARSVA(SARS-CoV-2). Trypsin cleaved all three peptides with varying efficiency. Furin, as expected from previous studies, cleaved the SARS-CoV-2 peptide; however, it did not cleave the LRNV or JC34 peptides (Figure 6). These data indicate that although AcCoVJC34 has a minimal furin cleavage sequence $(\mathrm{R}-\mathrm{X}-\mathrm{X}-\mathrm{R})$ it is not able to be cleaved by furin when tested experimentally. 


\section{Discussion}

The "furin cleavage site" or FCS of SARS-CoV-2 has been at the center of the many discussions on the origin of the COVID-19 pandemic; see [11] for a recent summary. Despite being interpreted as "highly unusual", an FCS is_-to the contrary-very common among the Coronaviridae [12], with sarbecoviruses and most alphacoronaviruses being the exception rather than the rule in lacking this important regulatory sequence. In fact, many zoonotic coronaviruses and those in reservoir hosts appear to contain sequences and structural loops at the S1/S2 interface that are sub-threshold for furin-mediated cleavage [13-16] and may be "poised" for spillover events. Examples include "pre-variant" SARS-CoV-2, as well as the sarbecoviruses RmYN02, RacCS203, BANAL-20-116, BANAL-20-246 that have potential phylogenetic homology to the SARS-CoV-2 FCS [17] — and may include the luchacovirus AcCoV-JC34 analyzed here. It is noteworthy that AcCoV-JC34 is the only luchacovirus containing this -R-RR- motif.

While containing an -RR-R- motif, as found in SARS-CoV-2, the data presented here show that this AcCoV-JC34 sequence is not cleaved by furin. The reasons for this are currently unclear. One possibility is that the upstream proline found in SARS-CoV-2, as well as in other spike cleavage site sequences, may promote cleavage by creating a structural turn beneficial for furin activity. It is also possible that the additional downstream arginine residue in AcCoVJC34 spike may be inhibitory for the tight active site binding pocket present in furin [18]. Alternatively, the structural loop present in AcCoV-JC34 spike may be cleaved by other proprotein convertases of the furin family that have less stringent cleavage requirements, or 
by trypsin-like enzymes or cathepsins. Notably, the -RR-R- motif is rare in furin substrates, and only other known example of this sequence motif in FurinDB (a database of furin substrates) is found in proaerolysin, a bacterial toxin [19].

One notable aspect of the -RR-R- motif in AcCoV-JC34 is that is does not align precisely with the S1/S2 motif of most coronavirus spikes (see Figure 3) and is a structurally exposed location above the typical S1/S2 loop (see Figure 4). Analysis of the MERS-CoV spike also shows an addition putative FCS in the MERS-CoV spike (SRSTRS); while this contains a minimal furin motif this sequence shows low scores for furin cleavage with both Pitou and ProP, and FRETbased peptides were not cleaved by furin in biochemical cleavage assays-in contrast to the PRSVRS motif at the expected S1 /S2 junction (J. K. Millet, unpublished results). Nevertheless, it is possible that, as with AcCoV-Jc34, this "secondary" MERS-CoV sequence comprises a "blocked" FCS due to flanking hydrophobic and charges residues in the downstream Cterminal positions (i.e., SRSTRSMLKRRDS). This putative secondary cleavage site also lacks an upstream proline/proline-rich region, as with many other S1/S2 regions that are known to be cleaved by furin.

For SARS-CoV-2, it is clear that selection is occurring to up-regulate the spike FCS, as seen with several of the highly transmissible variants that have emerged [20-24]. The FCS can also be readily down regulated upon Vero cell adaptation; for examples see refs [25, 26]. Likewise, some coronaviruses in animal reservoirs may be "poised" for proteolytic cleavage-activation at S1/S2, with selection occurring along with modifications to their receptor binding domain. One interesting example of this may exemplified by the MERS-like bat-CoVs HKU-4 and 
HKU-5, with HKU-4 binding human DPP4, but having no identifiable FCS, and with HKU5 not able to bind hDPP4 and having a robust FCS [27].

Our studies highlight the possible presence of a distinct proteolytic cleavage loop in the coronavirus spike protein and the specific features of the luchacovirus spike-which along with that found in the rhinacoviruses (e.g., SADS-CoV) appears to represent an evolutionary disparate spike protein with apparent similarities to a betacoronavirus spike protein (see Figure 1), despite the taxonomic designation of these viruses as alphacoronaviruses. 


\section{References}

1. Ruiz-Aravena, M., et al., Ecology, evolution and spillover of coronaviruses from bats. Nature Reviews Microbiology, 2021.

2. Plowright, R.K., et al., Pathways to zoonotic spillover. Nat Rev Microbiol, 2017. 15(8): p. 502-510.

3. Stout, A.E., et al., Viral and Host Attributes Underlying the Origins of Zoonotic Coronaviruses in Bats. Comparative Medicine, 2021. 71: p. 442-450.

4. Luis, A.D., et al., A comparison of bats and rodents as reservoirs of zoonotic viruses: are bats special? Proc Biol Sci, 2013. 280(1756): p. 20122753.

5. Keeling, M.J. and C.A. Gilligan, Metapopulation dynamics of bubonic plague. Nature, 2000. 407(6806): p. 903-906.

6. Wang, W., et al., Discovery, diversity and evolution of novel coronaviruses sampled from rodents in China. Virology, 2015. 474: p. 19-27.

7. Ge, X.Y., et al., Detection of alpha- and betacoronaviruses in rodents from Yunnan, China. Virol J, 2017. 14(1): p. 98.

8. Wu, Z., et al., Comparative analysis of rodent and small mammal viromes to better understand the wildlife origin of emerging infectious diseases. Microbiome, 2018. 6(1): p. 178.

9. Tsoleridis, T., et al., Shared Common Ancestry of Rodent Alphacoronaviruses Sampled Globally. Viruses, 2019. 11(2).

10. Stout, A.E., et al., Furin cleavage sites in the spike proteins of bat and rodent coronaviruses: Implications for virus evolution and zoonotic transfer from rodent species. One Health, 2021. 13: p. 100282.

11. Chan, Y.A. and S.H. Zhan, The emergence of the spike furin cleavage site in SARSCoV-2. Molecular Biology and Evolution, 2021.

12. Whittaker, G.R., SARS-CoV-2 spike and its adaptable furin cleavage site. Lancet Microbe, 2021. 2(10): p. e488-e489.

13. Jaimes, J.A., et al., Phylogenetic Analysis and Structural Modeling of SARS-CoV-2 Spike Protein Reveals an Evolutionary Distinct and Proteolytically Sensitive Activation Loop. J Mol Biol, 2020. 432(10): p. 3309-3325.

14. Jaimes, J.A., J.K. Millet, and G.R. Whittaker, Proteolytic Cleavage of the SARS-CoV-2 Spike Protein and the Role of the Novel S1/S2 Site. iScience, 2020. 23(6): p. 101212.

15. Tang, T., et al., Proteolytic Activation of SARS-CoV-2 Spike at the S1/S2 Boundary: Potential Role of Proteases beyond Furin. ACS Infect Dis, 2021. 7(2): p. 264-272.

16. Millet, J.K. and G.R. Whittaker, Host cell entry of Middle East respiratory syndrome coronavirus after two-step, furin-mediated activation of the spike protein. Proc Natl Acad Sci U S A, 2014. 111(42): p. 15214-9. 
17. Lytras, S. https://virological.org/t/the-sarbecovirus-origin-of-sars-cov-2-s-furincleavage-site/536.

18. Henrich, S., et al., The crystal structure of the proprotein processing proteinase furin explains its stringent specificity. Nat Struct Biol, 2003. 10(7): p. 520-6.

19. Abrami, L., et al., The pore-forming toxin proaerolysin is activated by furin. J Biol Chem, 1998. 273(49): p. 32656-61.

20. Bushman, M., et al., Population impact of SARS-CoV-2 variants with enhanced transmissibility and/or partial immune escape. Cell, 2021.

21. Lubinski, B., et al., Spike protein cleavage-activation mediated by the SARS-CoV-2 P681R mutation: a case-study from its first appearance in variant of interest (VOI) A.23.1 identified in Uganda. bioRxiv, 2021: p. 2021.06.30.450632.

22. Lubinski, B., et al., Functional evaluation of the P681H mutation on the proteolytic activation the SARS-CoV-2 variant B.1.1.7 (Alpha) spike. iScience 2021 https://doi.org/10.1016/j.isci.2021.103589

23. Grubaugh, N.D., et al., Public health actions to control new SARS-CoV-2 variants. Cell, 2021. 184(5): p. 1127-1132.

24. Lauring, A.S. and E.B. Hodcroft, Genetic Variants of SARS-CoV-2-What Do They Mean? JAMA, 2021. 325(6): p. 529-531.

25. Sasaki, M., et al., SARS-CoV-2 variants with mutations at the S1/S2 cleavage site are generated in vitro during propagation in TMPRSS2-deficient cells. PLoS Pathog, 2021. 17(1): p. e1009233.

26. Lamers, M.M., et al., Human airway cells prevent SARS-CoV-2 multibasic cleavage site cell culture adaptation. Elife, 2021. 10.

27. Yang, Y., et al., Receptor usage and cell entry of bat coronavirus HKU4 provide insight into bat-to-human transmission of MERS coronavirus. Proc Natl Acad Sci U S A, 2014. 111(34): p. 12516-21. 


\section{Methods}

Furin prediction calculations. Prop: CoV sequences were analyzed using the ProP 1.0 Server hosted at: cbs.dtu.dk/services/ProP/. PiTou: CoV sequences were analyzed using the PiTou V3 software hosted at: http://www.nuolan.net/reference.html.

\section{Amino acid alignments and phylogenetic trees}

Multiple sequence alignment was performed on coronavirus spike protein using Geneious Prime ${ }^{\circledR}$ (v.2019.2.3. Biomatters Ltd.). A maximum likelihood phylogenetic tree was constructed using MegaX(, 100 boot strap replicates based on the spike protein. Amino acid sequences of $\mathrm{S}$ were obtained from NCBI GenBank. Accession numbers are: AcCoV-Jc34 (YP_009380521), Asian leopard cat CoV (EF584908.1),Bat_Hp/Zhejiang2013(YP_009072440),Bat-Rm/Yunnan/YN02/2019

(QPD89843.1), Bat-SL-CoV_ZC45 (AVP78031.1), BCoV (P15777), Bottlenose dolphin CoVHKU22 (AHB63508), BtRf-AlphaCoV/YN2012 (YP_009200735), CCoV (AY436637.1), ECoVNC99 (AAQ67205.1), FCoV-Black (EU186072.1), Ferret-CoV (NC_030292.1), FIPV 79-1146 (DQ010921.1),HCoV-229E(NC_002645.1),HCoV-HKU1(NC_006577),HCoV-

NL63(NC_005831.2),HCoVOC43(NC_006213.1),HeCoV(MK679660.1),HKU4(YP_001039953),H KU5(YP_001039962), HKU23(QEY10673),HKU24(QOE77327), IBV(NC_001451.1), Longquan Rl rat $\mathrm{CoV}$ (QOE77336.1), Lucheng Rn rat CoV(QOE77268.1), MERS-CoV(AFS88936.1), MHV-1 (ACN89742), PDCoV (MN942260.1), PEDV(NC_003436.1), PHEV(QTF73995.1), Porcine enteric alphacoronavirus GDS04 (ASK51717.1), Rabbit CoV-HKU14(AFE48827), RaTG13(QHR63300), Rhinolophus bat coronavirus HKU2 (YP_001552236.1), Rhinolophus bat CoV-BTKY72 (APO40579.1), Rhinolophus bat CoV-HKU32 (QCX35178), Rhinolophusbat CoV-HKU2 (YP_001552236.1), Rousett bat CoV-229E related(QHA24665), Rousettus bat CoVGCCDC1(QKF94914), RtClan-CoV/GZ2015 0, RtMurf-CoV-1/JL 2014 (ATP66738), RtRl-CoV/F J2015 (KY370050), SARS-CoV (AAT74874.1), SARS-CoV-2 Wuhan-Hu-1 (YP_009724390.1), Sc- 
BatCoV-512 (ABG47078), Swine acute diarrhea syndrome coronavirus(AVM41569.1), Swine acute diarrhea syndrome related coronavirus (AVM80500.1), TGEV(P07946), Turkey-CoV (QRR19172), UkMa1(QBG64648), UKRn3(QBG64657).

\section{Spike structural modelling}

Pairwise amino acid alignment between AcCoV-Jc34 (YP_009380521) and SADS-CoV (AVM80500) was performed using Geneious Prime ${ }^{\circledR}$ (v.2019.2.3. Biomatters Ltd.). S protein models were built based on the SADS-CoV structure obtained from RCSB (PDB: 6M39), using UCSF Chimera (v.1.14, University of California) through the modeler homology tool of the Modeller extension (v.9.23, University of California).

\section{Fluorogenic peptide cleavage assays}

Fluorogenic peptide cleavage assays were performed as described previously [14]. Each reaction was performed in a $100 \mu \mathrm{L}$ volume consisting of buffer, protease, and AcCoV-Jc34 (TFSRRARARTL) or Lucheng Rn rat CoV (TFMTKARARTTF) or SARS-CoV-2 S1/S2 WT (TNSPRRARSVA) fluorogenic peptide in an opaque 96-well plate. For trypsin catalyzed reactions, $0.8 \mathrm{nM} /$ well TPCK trypsin was diluted in PBS buffer. For furin catalyzed reactions, $1 \mathrm{U} /$ well recombinant furin was diluted in buffer consisting of $20 \mathrm{mM}$ HEPES, $0.2 \mathrm{mM} \mathrm{CaCl}$, and $0.2 \mathrm{mM} \beta$-mercaptoethanol, at pH 7.0. Fluorescence emission was measured once per minute for 60 minutes using a SpectraMax fluorometer (Molecular Devices) at $30^{\circ} \mathrm{C}$ with an excitation wavelength of $330 \mathrm{~nm}$ and an emission wavelength of $390 \mathrm{~nm}$. Vmax was calculated by fitting the linear rise in fluorescence to the equation of a line. 


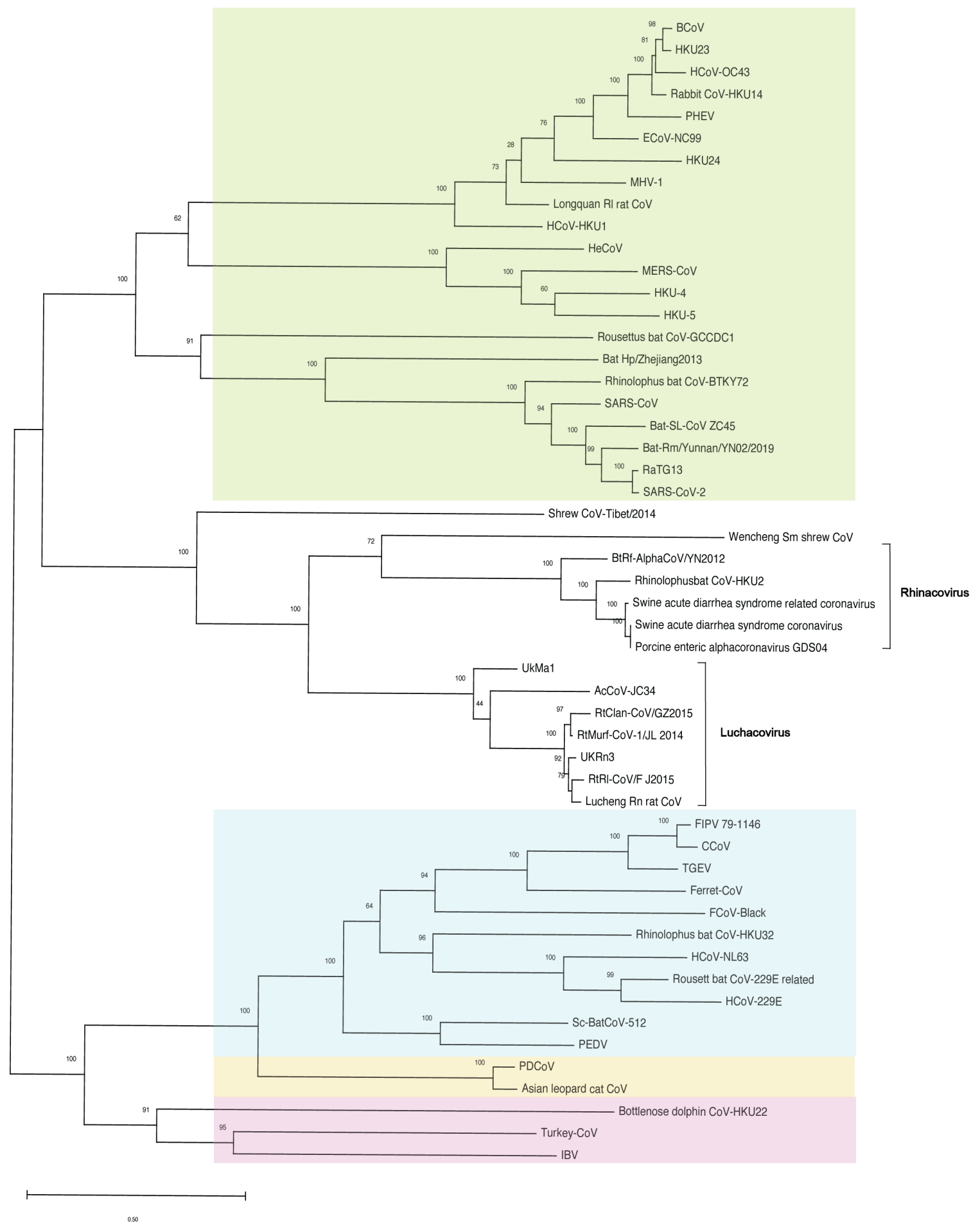

\section{Figure 1. Phylogenetic tree of spike protein sequences.}

The maximum likelihood phylogenetic tree was constructed using MegaX, 100 bootstraps, from a multiple sequence alignment of the spike sequences. Betacoronavirus spikes are shaded green, alphacoronavirus spikes are shaded blue, deltacoronavirus spikes are shaded yellow and gammacoronavirus spikes are shaded pink 
bioRxiv preprint doi: https://doi.org/10.1101/2021.12.16.473025; this version posted December 20, 2021. The copyright holder for this preprint (which was not certified by peer review) is the author/funder, who has granted bioRxiv a license to display the preprint in perpetuity. It is made available under aCC-BY-NC-ND 4.0 International license.

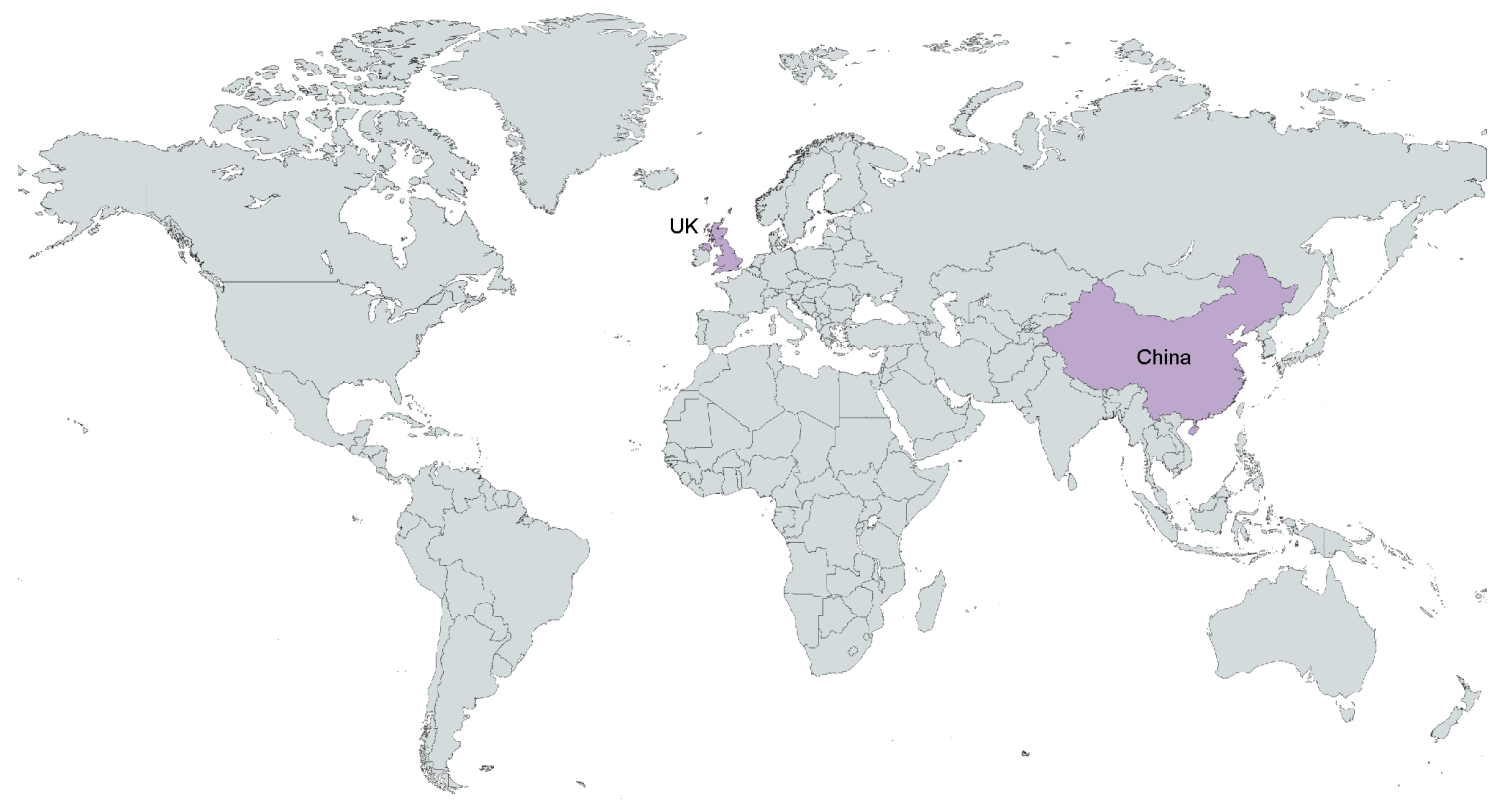

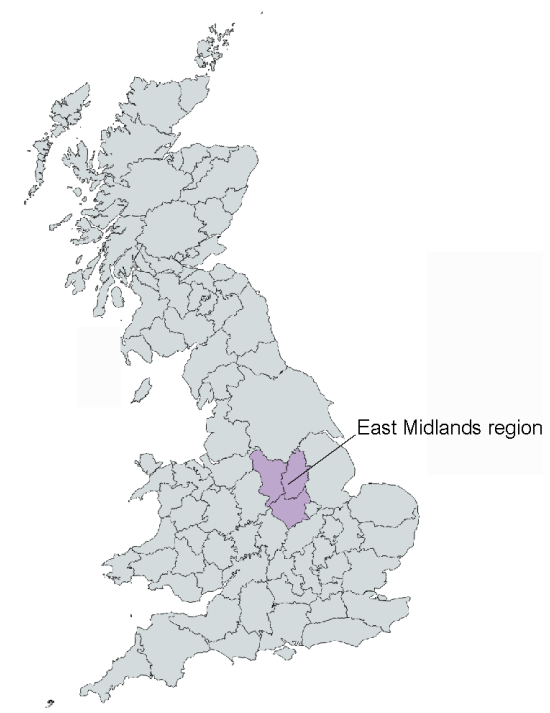

United Kingdom

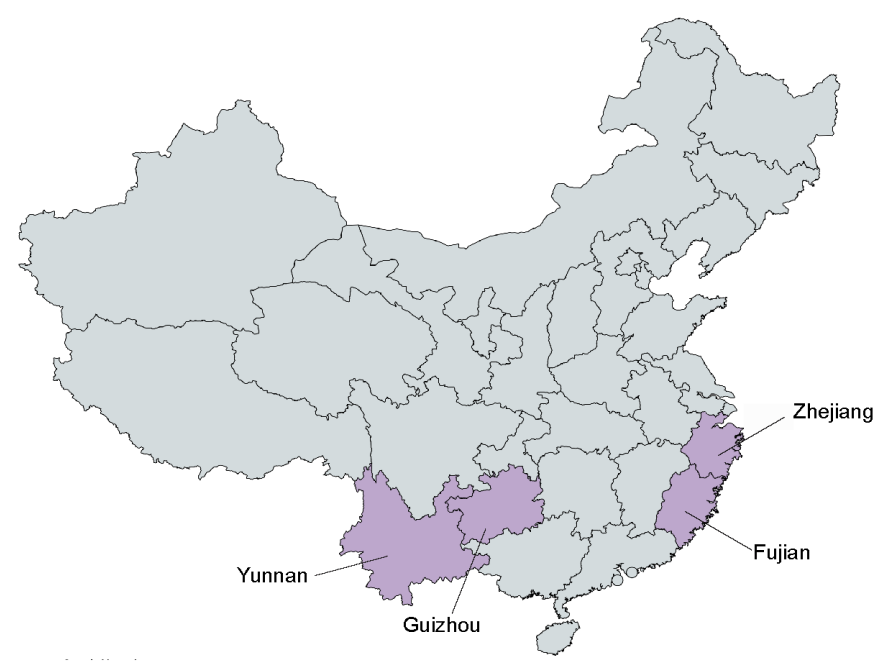

China

Figure 2. Geographical distribution of currently identified luchacoviruses.

Luchacoviruses have been identified from surveillance studies in United Kingdom (East Midlands region) and China (Yuanna, Zhejiang, Fujian, Jilin, and Guizhou provinces). 
bioRxiv preprint doi: https://doi.org/10.1101/2021.12.16.473025; this version posted December 20, 2021. The copyright holder for this preprint (which was not certified by peer review) is the author/funder, who has granted bioRxiv a license to display the preprint in perpetuity. It is made available under aCC-BY-NC-ND 4.0 International license.

\begin{tabular}{llll} 
Luchacovirus & $\begin{array}{l}\text { Rodent } \\
\text { species }\end{array}$ & Location & Time period \\
\hline AcCoV-JC34 & Apodemus chevrieri & China (Yuanna) & 2011.8 \\
Lucheng Rn rat CoV & Rattus norvegicus & China (Lucheng) & $2011-2013$ \\
RtRl-CoV/FJ2015 & Rattus losea & China (Fujian) & 2015.5 \\
RtMruf-CoV-1/JL2014 & Myodes rufocanus & China (Jilin) & 2014.8 \\
RtClan-CoV/GZ2015 & Eothenomys melanogaster & China (Guizhou) & 2015.12 \\
& & United & $2008-2015$ \\
UKRn3 & Rattus norvegicus & Kingdom & \\
UKMa1 & Microtus agrestis & United & Kingdom \\
\hline
\end{tabular}

Table 1. Rodent luchacoviruses identified from surveillance studies. 
bioRxiv preprint doi: https://doi.org/10.1101/2021.12.16.473025; this version posted December $20,2021$. The copyright holder for this preprint (which was not certified by peer review) is the author/funder, who has granted bioRxiv a license to display the preprint in perpetuity. It is made available under aCC-BY-NC-ND 4.0 International license.

\section{Figure 3}

AcCoV-JC34

Lucheng $\mathrm{Rn}$ rat $\mathrm{CoV}$

SARS-COV- 2

SARS-COV

HKU 1

OC43

MERS-COV

AcCoV-JC34

Lucheng $\mathrm{Rn}$

SARS-COV- 2

SARS-COV

HKU 1

OC43

MERS-CoV
- - - - MAL IFVLML ITLYRCPFVLCNFQVCTDQLRQQ - - - - - - - - - - - - EVYL - PNAVS

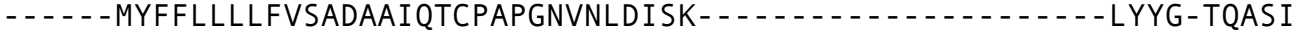

- - - - MFVFLVLLPLVSSQCVNLTTRTQ - - LPPAYTN - - - - - - - - - - SFTRGVYYP-DKVFR

- - - MAIFLLFLTLTSGSDLDRCTTFDDVQAPNYTQ - - - - - - - HTSSMRGVYYP-DEIFR - - - - MLL I I F I LPTTLAVIGDFNCTNFAINDLNTTV- - - - - PRISEYVVDVSYGLGTYYILDRVYL - - - - MFL I LL I SLPTAFAVI GDLNCTLDPRLKGSFNN - -RDTGPPS I SIDTVDVTNGLGTYYVLDRVYL MIHSVFLLMFLLTPTESYVDVGPDSVKSACIEVDIQQTFFDKTWPR - - - PIDVSKADG I IYPQGRTYS
41

40

44

48

57

63

65

86

83

100

97

118

124

132

118

120

135

132

155

173

186

166

172

199

194

198

217

251

208

215

265

252

256

273

313

275

282

333

320

325

342

382

330

337

399

386

390

407

445
AcCoV-JC34 Lucheng $\mathrm{Rn}$ rat $\mathrm{CoV}$ SARS-COV-2 SARS-COV HKU 1

OC43

MERS-COV NLCPFGEVFNATKFPSVYAWE - - RKKI SNCVADYSVLYNSTFFSTFKCYGVSATKLNDLCFSNVYADS D-CDIDKWLNNFNVPSPLNWE - - RKIFSNCNFNLSTLLRLVHTDSFSCNNFDESKIYGSCFKS IVLDK N-CNIEAWLNDKSVPSPLNWE - - RKTFSNCNFNMSSLMSF I QADSFTCNN I DAAKIYGMCFSSITIDK - - CDFSPLLSGTP-PQVYNFK - - RLVFTNCNYNLTKLLSLFSVNDFTCSQISPAAIASNCYSSLILDY
372

379

459

446

454

476

503 
bioRxiv preprint doi: https://doi.org/10.1101/2021.12.16.473025; this version posted December $20,2021$. The copyright holder for this preprint (which was not certified by peer review) is the author/funder, who has granted bioRxiv a license to display the preprint in perpetuity. It is made available under aCC-BY-NC-ND 4.0 International license.

AcCoV- JC34

SARS-COV- 2

SARS-COV

HKU 1

OC43

MERS-COV
Lucheng $\mathrm{Rn}$ rat CoV
- - - - - - OFNPDAYTPDYM- - EC -

- - - - - - - SFDVNSYTPDYM- - EC - - - - - - - - - - - - - - - - - - - - - - - -

- - NLKPFERDISTEIYQAGST - - PC - - - - - -

- - - KLRPFERDI SNVPFSPDGK- - PC - - - - -

- - - LSSHSVVYSRYCFSVNNTFCPCAKPSFASSCKSHKPPSASCPIGTNYRSCESTTVLDHTDWCRCS PTGVFTNHSVVYAQHCFKAPKNFCPC - - - - SSCPGKNNGIGTCPAGTNSLTCDNLCTLD - - - - - -SRLLSDDRTEVPQLVNANQYS - PC - . . .
386

393

480

467

519

531

528

405

412

514

500

588

592

570

454

461

571

557

655

659

636

(JC34 -RR-R- motif)

ACCOV-JC34 DMVSH--VRIKGIVYSVEPCNSFYYSV- - - LKTRSEVGYLYSGANCNSSDVVT- - FSRRARARTLTDS Lucheng Rn rat CoV DMVSY--VRIRGVVYAVESCNRFYYSV----FKTLSAIGYLYSGATCDSTDVTT--FMTKAKATTFVDS SARS-COV-2 TTDAVRDPQTLEI - LDITPCSFGGVSVITPGTNTSNQVAVLYQDVNCTEVPVAI - - HADQLTPTWRVYS SARS-COV FTDSVRDPKTSEI - LDISPCSFGGVSVITPGTNASSEVAVLYQDVNCTDVSTAI - - HADQLTPAWRIYS HKU 1 NIIGFKDFVTNKT-YNIFPCYAGRVSAAF - -HQNASSLALLYRNLKCSYVLNNI-- - -SLTTQPYFDS $0 C 43$ NLYGFRDYITNRT - FMIHSCYSGRVSAAY - - HANSSEPALLFRNIKCNYVFNNS - - LTRQLQPINYSFD MERS-COV NLVGY - -YSDDGNYYCLRACVSVPVSVIY - -DKETKTHATLFGSVACEHISSTMSQYSRSTRSMLKRRD

\section{S1 I S2}

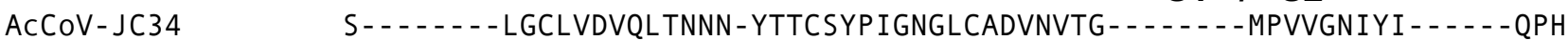

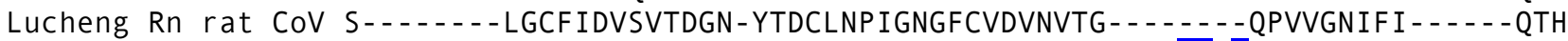
SARS-COV-2 TGSNVFQTRAGCLIGAEHVNN--SYECDIPIGAGICASYQTQT-NSPRRARSVASQSIIAYTMSLGAEN SARS-COV TGNNVFQTQAGCLIGAEHVDT--SYECDIPIGAGICASYHTVSLL-_---RSTSQKSIVAYTMSLGADS HKU 1 $0 \mathrm{C} 43$ MERS-COV Y - - - - - LGCVFNADNLTDYSVSSCALRMGSGFCVDYNSPSSSSSRRKRRSI SASYRFVTF - - - EPF S- - - - - - YLGCVVNAYNSTAISVQTCDLTVGSGYCVDYFKNR - - - RSRRAITTGYRFTNF - - - EPF STYGPLQTPVGCVLGLVNSSLF - VEDCKLPLGQSLCALPDTPSTLTPRSVRSVPGEMRLASIAFNHPI -

AcCoV-JC34 DTDYARPILSPQ - - - IVSLPLDHVINVKEQFVQTSAPKFDVDCERYICDVSVQCKELLAKYGGYCPKI Lucheng Rn rat CoV DTDYARPILTAQ----QIELPIDHYVSVKEQFIQTSTPKFDVDCERYICDVSSDCRELLVKYGGYCSKI SARS - COV - 2 SARS-COV HKU 1 $0 \mathrm{C} 43$ MERS-COV SVAYSNNS - - - - - - IAIPTNFTI SVTTE I LPVSMTKTSVDCTMY ICGDSTECSNLLLQYGSFCTQL SIAYSNNT - - - - - - IAIPTNFSISITTEVMPVSMAKTSVDCNMYICGDSTECANLLLQYGSFCTQL NVSFVNDSIESVGGLYE IKI PTNFT IVGQEEF IQTNSPKVT IDCSLFVCSNYAACHDLLSEYGTFCDNI TVNSVNDSLEPVGGLYEIQIPSEFTIGNMEEFIQTSSPKVTIDCAAFVCGDYAACKLQLVEYGSFCDNI QVDQLNSS - - - - -YFKLSIPTNFSFGVTQEYIQTTIQKVTVDCKQYVCNGFQKCEQLLREYGQFCSKI

S2'

(FP)

AcCoV-JC34 VSDIKSSSLQLDYQVQG IYKTLNVDVKVPDV-DFG-AFNF - - - - - - - SMFESEPNGRSFIEDIL Lucheng Rn rat CoV LADIKSSSIQLDYQILGLYKTLAVDFKVPDI-DFG-DFNF_-........ - SMYMSEANGRSFIEDLL SARS-COV-2 NRALTGIAVEQDKNTQEVFAQVKQIYKTPPIKDFG-GFNF - - _. - - - SQILPDPSKPSKRSFIEDLL SARS-COV HKU 1 $0 \mathrm{C} 43$ MERS-COV NRALSGIAAEQDRNTREVFAQVKQMYKTPTLKYFG-GFNF - - - - - - -SQILPDPLKPTKRSF I EDLL NSI LDEVNGLLDTTQL HVADTLMQGVTLSSNLNTNLHFDVDNINFKSLVGCLGPHCGS - SSRSFFEDLL NAILTEVNELLDTTQLQVANSLMNGVTLSTKLKDGVNFNVDDINFSPVLGCLGSECSKASSRSAIEDLL NQALHGANLRQDDSVRNLFASVKSSQSSPI I PGFGGDFNL - - - - - TLLEPVSISTGSRSARSAIEDLL
515

522

637

623

716

723

701

561

568

703

685

774

777

768

626

633

763

745

843

846

831

681

688

822

804

911

915

894 
bioRxiv preprint doi: https://doi.org/10.1101/2021.12.16.473025; this version posted December $20,2021$. The copyright holder for this preprint (which was not certified by peer review) is the author/funder, who has granted bioRxiv a license to display the preprint in perpetuity. It is made available under aCC-BY-NC-ND 4.0 International license.

fusion peptide (FP)

AcCoV-JC34 FDKIVTTGPGFYQDYYDCK---KMNLEDITCKQYYNGIMVIPPVMDDTLITFWSSA-VAGSMTAGLFGG Lucheng Rn rat CoV FDKIVTTGPGFYQDYYDCK---KMNLQDLTCKQYYNGIMVIPPVMDDTLITFWSSA-VAGSMTAGLFGG SARS-COV-2 FNKVTLADAGFIKQYGDCL - GDIAARDLICAQKFNGLTVLPPLLTDEMIAQYTSALLAGTITSGWTFG SARS-COV FNKVTLADAGFMKOYGECL - GDINARDLICAOKFNGLTVLPPLLTDDMIAAYTAALVSGTATAGWTFG HKU 1

$0 \mathrm{C} 43$

MERS-COV

AcCoV-JC34 - -QAGMVSWSIAVAGRLNALGVMQDALVNDVNKLANGFNNLTQYVADGFKTTSQALSAIQSVVNNNAQQ Lucheng Rn rat CoV --QAGMVSWTVALAGRLNALGVMQDALVEDVNKLANGFNNLTQYVSDGFKTTSQALSTIQAVVNNNAQQ SARS-COV-2 AGAALQIPFAMQMAYRFNGIGVTQNVLYENQKLIANQFNSAIGKIQDSLSSTASALGKLQDVVNQNAQA SARS - COV HKU 1 $0 \mathrm{C} 43$ AGAALQIPFAMQMAYRFNG IGVTQNVLYENQKQIANQFNKAISQIQESLTTTSTALGKLQDVVNQNAQA - -AAAGIPFSLNVQYRINGLGVTMDVLNKNQKL IATAFNNALLSIQNGFSATNSALAKIQSVVNSNAQA - -AAAGVPFYLNVQYRINGLGVTMDVLSQNQKL IANAFNNALHAIQQGFDATNSALVKIQAVVNANAEA MERS-COV LSSFAAI PFAQS I FYRLNGVGITQQVLSENQKL IANKFNQALGAMQTGFTTTNEAFQKVQDAVNNNAQA LNTLVKQLSSNFGA I SSVLNDVL SRLDKVEAEVQI DRL ITGRLQSLQTYVTQQL I RAAE I RASANLAAT HKU 1

$0 \mathrm{C} 43$ LNSLLQQLFNKFGAISSSLQE I LSRLDALEAQVQIDRL INGRLTALNAYVSQQLSDISLVKFGAALAME LNNLLQQL SNRFGAI SASLQE I LSRLDALEAEAQIDRL INGRLTALNAYVSQQL SDSTLVKFSAAQAME

MERS-COV KMSECVLGQSKRVDFCGKGYHLMSFPQAAPHGVVFLHVTYVPSQERNFTTAPAICHEGK-- - AYFPREG KVNECVKSQSPRINFCGNGNHILSLVQNAPYGLLFMHFSYKPISFKTVLVSPGLCISGD - -VG IAPKQG

HKU 1

OC43 KVNECVKSQSSRINFCGNGNH I I SLVQNAPYGLYF I HFNYVPTKYVTAKVSPGLCIAGN - - RG IAPKSG MERS-COV KVNECVKAQSKRSGFCGQGTHIVSFVVNAPNGLYFMHVGYYPSNHIEVVSAYGLCDAANPTNCIAPVNG

AcCoV-JC34

LFVKTNIRSDV - -WHFTTRNLYNPQAITVNNSVIVNG - GVNFTSLNQTIEGIEPPTIPS - -FDEEFEDL Lucheng $\mathrm{Rn}$ rat CoV LFVRLSTARDTD-WHFTTRNRYSPEPITVNNTLTISG-GVNFTVVNSTIDGIEPPANPS--FDEEFAEL SARS-COV- 2 SARS-COV VFVSNGTH- - - -WFVTQRNFYEPQI I TTDNTFVSGNCDVVIGIVNNTVYDPLQPELDS - - FKEELDKY VFVFNGTS - - - -WF ITQRNFFSPQI ITTDNTFVSGNCDVVIGI INNTVYDPLQPELDS - - FKEELDKY YFIKHNDH - - - -WMFTGSSYYYPEPISDKNVVFMNTCSVNFTKAPLVYLNHSVPKLSD--FESELSHW YFVNVNNT - - - -WMYTGSGYYYPEPITENNVVVMSTCAVNYTKAPYVMLNTSIPNLPD - FKEELDQW $0 \mathrm{C} 43$ MERS-COV YFIKTNNTRIVDEWSYTGSSFYAPEP ITSLNTKYVAP - QVTYQNISTNL PPPLLGNSTGIDFQDELDEF Lucheng Rn rat CoV YKNVTLELEQLK-NIS-FDPEMLNLTYYIDRLDELATNVSQLHVDVSEFNKFVQYIKWPWYVWLAIFLV SARS - COV- 2 SARS - COV HKU 1 OC43 FKNHTSPDVDLG-DISG INASVVNIQKE IDRLNEVAKNLNESL IDLQELGKYEQY IKWPWY IWLGF IAG FKNHTSPDVDLG-DISG INASVVNIQKE I DRLNEVAKNLNESL IDLQELGKYEQY IKWPWYVWLGF IAG FKNQTS IAPNLTLNLHT INATFLDLYYEMNL IQES IKSLNNSY INLKDIGTYEMYVKWPWYVWLL ISFS FKNQTSVAPDL - - SLDY INVTFLDLQVEMNRLQEAIKVLNHSY INLKDIGTYEYYVKWPWYVWLL ICLA MERS-COV FKNVSTSIPNFG - SLTQINTTLLDLTYEML SLQQVVKALNESYIDLKELGNYTYYNKWPWY IWLGF IAG LIAIVMVT IMLCCMTSCCSCLKGC-CSCGSCCKFDEDDSEPVLKGVKLHYT F I IFLVLLFF ICCCTGCGSACF - - - SKCHNCCDEYGGHHDFVIKTSHDD - - 

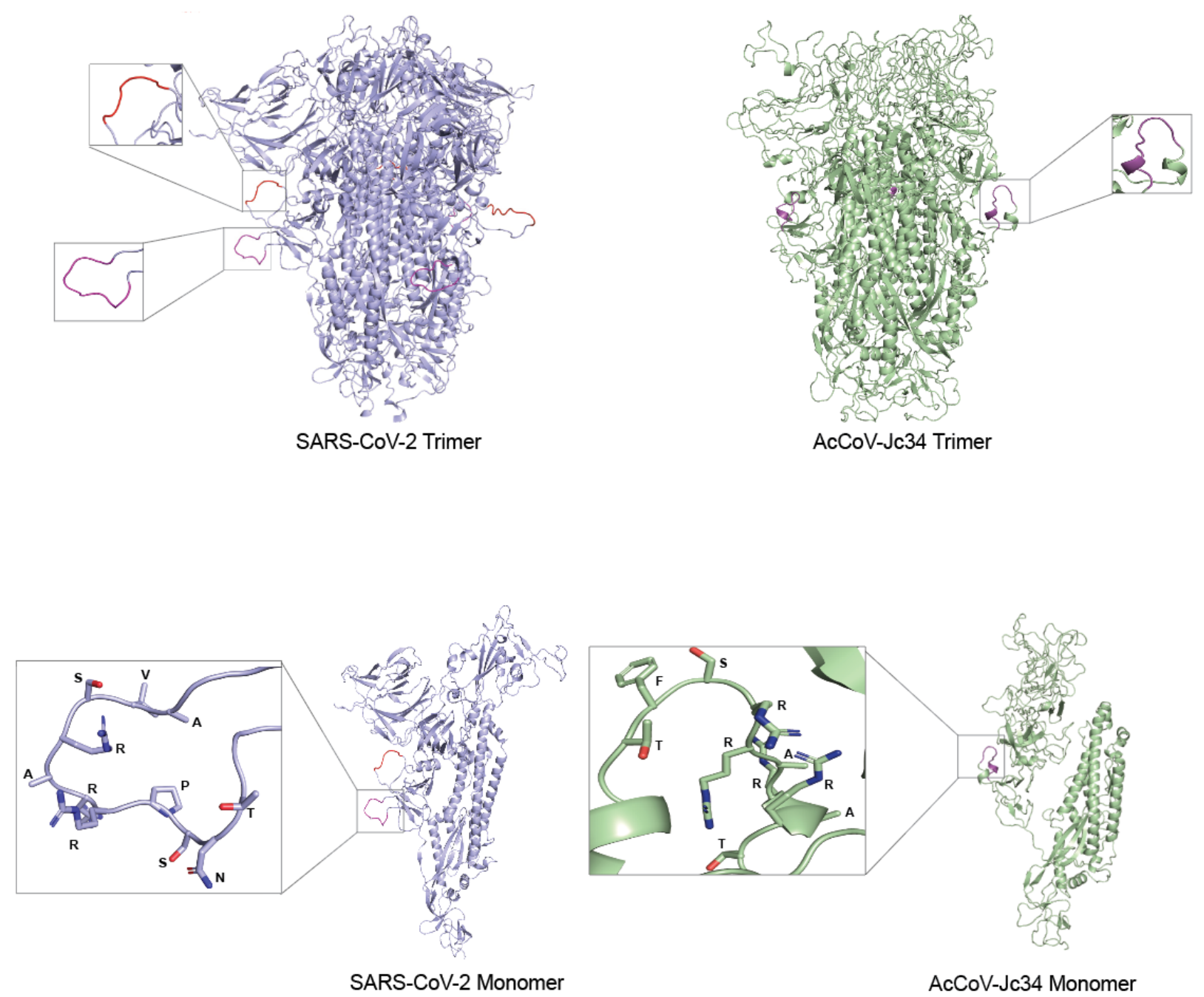

AcCoV-Jc34 Monomer

\section{Figure 4. Predicted structure of AcCoV-JC34 spike protein.}

The AcCoV-JC34 spike protein was modelled based on SADS-CoV spike. In SARS-CoV-2, the pink highlight indicates where the furin cleavage sequence (PRRAR) is located. The red highlight is the location that aligns with AcCoV-JC34 potential furin cleavage site. In the AcCoV-JC34 structural model, the pink highlight indicates location of the potential furin cleavage site (SRRAR). 


\begin{tabular}{|c|c|c|c|}
\hline Virus & Predicted S1/S2 sequence & PiTou & ProP \\
\hline$\overline{\mathrm{AcCoV}-\mathrm{JC} 34}$ & 495 - CNSSDVVTFSRRAR|ARTLTD - 514 & +0.15 & 0.279 \\
\hline Lucheng $\mathrm{Rn}$ rat $\mathrm{CoV}$ & 502 - CDSTDVTTFMTKAR|ATTFVD - 521 & -4.577 & 0.132 \\
\hline MERS-CoV & 681 - HISSTMSQYSRSTR|SMLKRR - 699 & -2.662 & 0.497 \\
\hline SARS-CoV-2 & 672 - ASYQTQTNSPRRAR|SVASQS - 691 & +9.196 & 0.62 \\
\hline SARS-CoV-1 & 654 - AGICASYHTVSLLR|STSQKS - 673 & -5.167 & 0.123 \\
\hline HCoV - HKU1 & 747 - YNSPSSSSSRRKRR|SISASY - 766 & +14.634 & 0.88 \\
\hline OC43 (clinical) & 750 - GYCVDYFKNRRSRR|AITTGY - 769 & +10.1 & 0.753 \\
\hline
\end{tabular}

Figure 5. Furin cleavage analysis of $\mathrm{CoV}$ S1/S2 cleavage site

$\mathrm{CoV} \mathrm{S}$ sequences were analyzed using the ProP 1.0 and PiTou 3.0 furin prediction algorithm, generating a score with bold numbers indicating predicted furin cleavage. ( | ) denotes the position of the predicted S1/S2 cleavage site. Basic resides, arginine $(\mathrm{R})$ and lysine $(\mathrm{K})$, are highlighted in blue. 
A

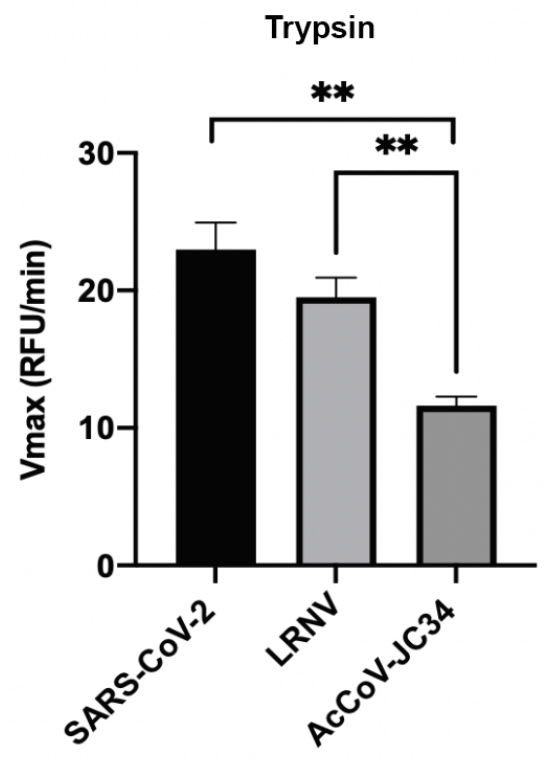

B

Furin

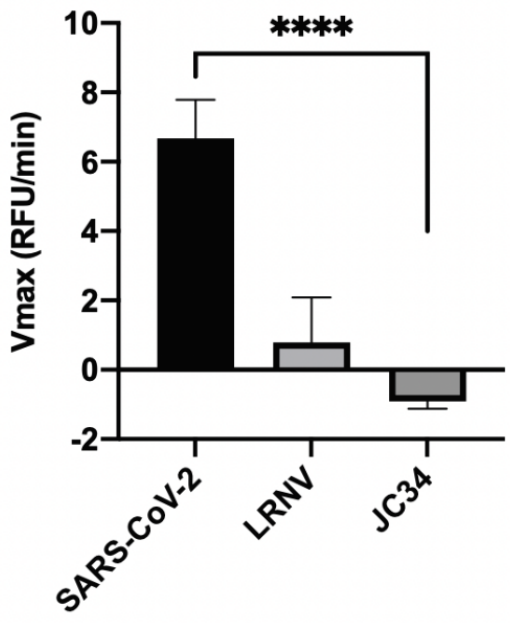

Figure 6. Fluorogenic peptide cleavage assays of the predicted AcCoV-JC34 furin cleavage site.

Peptides mimicking the S1/S2 site of the SARS-CoV-2 WT, AcCoV-JC34, and Lucheng Rn rat CoV (LRNV) were evaluated for in vitro cleavage with A) trypsin and B) furin proteases under $\mathrm{pH} 7.4$ (trypsin), and 7.5 (furin) conditions. Trypsin cleaved all three peptides, while furin only cleaved SARSCoV-2. 


\section{Acknowlegements:}

DTS is supported by the Howard Hughes Medical Institute-Cornell University Transfer (HHMICURT) program

AES was supported by NIH Comparative Medicine Training Program T32OD011000.

Work in the author's lab is funded in part by the National Institute of Health research grant R01AI35270 (to GW).

We thank the members of the Whittaker Lab, past and present, for their helpful discussions during the preparation of this manuscript. 